\title{
There is No Such Thing as "Going
} Back"

\section{KERRY F. CRAWFORD | JAMES MADISON UNIVERSITY}

\section{LEAH CATHRYN WINDSOR | THE UNIVERSITY OF MEMPHIS}

The following was originally published in APSA Educate's Pandemic Teaching series. The views expressed below are the guest contributors' and do not represent APSA's views. To contribute to the series, please send pitches or drafts to Bennett Grubbs, bgrubbs@apsanet.org

olleges and universities in the United States are desperate to "return to normal" after three semesters of teaching and learning during the COVID-19 pandemic. Faculty, staff, and students have weathered all the disruptions, challenges, and stress that accompany the effort to carry on with higher education while everyone grappled with the effects of local and global trauma brought on by the pandemic. This includes contracting COVID-19 themselves, losing family, friends, and loved ones to the virus, adapting to the stress of virtual education, and adapting to myriad family, social, financial, and caregiving crises and responsibilities.

We don't think colleges and universities should make a "return to normal" the goal. The pandemic has laid bare the dysfunction in society and in academia with regards to accommodating scholars and students with caregiving burdens. Such an effort to restore or reset campuses to their pre-pandemic versions ignores all that we have learned in the past eighteen months and obscures the reality that we are still very much in the midst of a global public health crisis.

Let's start with a few reality checks:

1. Parents and caregivers, especially of children under age 12 , are not out of the woods by any stretch. Many parents are caught between school boards, governors, and students in quarantine where masks are not mandated. Young children cannot be vaccinated yet, but we are now expected to work, teach, create scholarship, and learn as if the pandemic were over. For many, the flexibility of remote teaching, which made it possible to care for children displaced from school and daycare, is no longer an option. Because the vaccines are miraculously effective so far, those who are fully vaccinated and
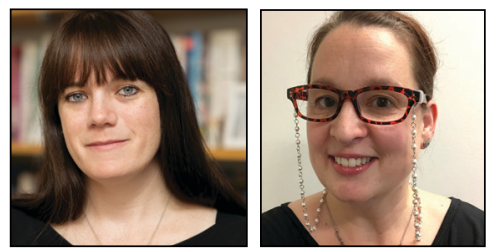
do not live with or care for young children or medically vulnerable loved ones are better able to compartmentalize the pandemic and carry on.

2. We must remember

Kerry F. Crawford is an associate professor of political science at James Madison University. She is the author of Wartime Sexual Violence (Georgetown University Press, 2017) and Human Security: Theory and Action. She is the mother of three young children-a dissertation baby and tenure dossier twins.

Leah Cathryn Windsor is an associate professor in the Department of English (Applied Linguistics) and the Institute for Intelligent Systems at The University of Memphis. She studies language patterns in international relations and is a non-resident fellow of the Krulak Center at the Marine Corps Academy. She is the mother of two young pre-tenure children.

Their book, The PhD Parenthood Trap: Caught Between Work and Family in Academia, is available from Georgetown University Press as of October 2021. that faculty, staff, and students who have unvaccinated, immunocompromised, or high-risk people in their households are not yet free to return to normal and are grappling with anxiety and daily risk calculations. Accommodations vary widely for faculty and students who have been exposed to or who have contracted COVID-19: some faculty are prohibited from teaching remotely; some are quietly encouraged to teach virtually while in quarantine.

3. People at higher risk for complications of COVID-19 themselves are not back to normal. Again, the return to pre-pandemic expectations for teaching, learning, and work modalities fails to recognize that the pandemic in some ways poses a greater threat now that many are abandoning precautions in the midst of a more transmissible variant than it did before when most people around us were taking public health precautions.

4. The COVID-19 pandemic is aptly considered a "triple pandemic" or a syndemic. Black and Latino households have been disproportionately affected by the virus and economic insecurity stemming from the pandemic, with both effects linked to systemic racism and structural inequality. Anti-Asian violence and xenophobia have surged in the United States and around the world throughout the pandemic. To return to normal without redressing these harms and their effects on the students, staff, and faculty in our campus communities would be a grave mistake.

5. International faculty, staff, and students have likely been unable to travel to see their families since before the start of the pandemic, their connections impeded by travel restrictions. The emotional burden of this long-term separation is intense.

6. Finally, the job market for political scientists is bleak, and will be for years, as a result of the pandemic. The backlog of talented scholars competing for limited permanent positions is daunting, and our discipline needs to do more to prepare students-from undergraduates to $\mathrm{PhDs}$ - for non-academic employment. The academic job market is dominated by contingent positions, instructorships, adjunct faculty, and visiting assistant professorships. Faculty in these positions are in precarious positions, with more professional demands and fewer protections, like health insurance and job security.

We can't simply return to normal. Keeping in mind that parents, caregivers, and those with medical conditions that place them at higher risk for complications from COVID-19 are not able to return to normal, that international faculty, staff, and students are still separated from loved ones, and that the pandemic has placed a heavier burden of disease, death, violence, and economic hardship on People of Color, pandemic teaching and learning in fall 2021 has to be different.

Such an effort to restore or reset campuses to their pre-pandemic versions ignores all that we have learned in the past eighteen months and obscures the reality that we are still very much in the midst of a global public health crisis.

We offer a few key recommendations for managing the coming semester as deftly as possible, with the reminder that none of us is likely to get through this semester without disruption. 


\section{FLEXIBILITY IS ESSENTIAL}

Instructional faculty should, to the extent possible, make syllabi and course plans "portable" and flexible so they can be converted from face-to-face to online or hybrid as needed. Even if your campus plans to resume fully face-to-face operations, students will get sick or need to quarantine after exposure to COVID-19, and you may be in this position yourself. If you're a parent or caregiver of a young child or children you may also find yourself at home with a sick or quarantined child. Plan for these disruptions and decide whether you'll continue class sessions synchronously, offer a remote option for sick or quarantined students, or post asynchronous content online for your students when you or they are unable to attend class in person. Pandemic teaching is at its core a lesson in flexibility with oneself and with one's students, colleagues, and family.

\section{ADOPT CHANGING TECHNIQUES}

Embrace the innovations we have made in teaching, research, and learning throughout the past eighteen months. Many of our colleagues did not know what Zoom was or how to use it before March 2020, and now they are adept at hosting meetings, sharing screens, and setting up breakout groups to run classes almost as smoothly as they do in person (give or take the occasional Wifi lag). Virtual conferences and workshops have made the exchange of ideas and research more accessible to scholars who do not have sufficient travel funding or who face visa barriers to attend in person. Virtual conferences and workshops are also far easier to attend with young children in tow, reducing the obstacles to parents' and caregivers' participation. Some conferences, as well as universities, have offered "participation grants" or compensation for technology upgrades for faculty and students needing accommodation for ADA reasons, for example. The pandemic has exposed the "digital divide" for low-income and rural students without access to high speed Internet. Faculty and universities should do their best to make the classroom accessible for everyone.

\section{KEEP AN OPEN LINE OF COMMUNICATION}

Communicate with students and colleagues early and openly. Because pandemic teaching requires so much flexibility and anticipation of contingencies, it also demands frequent, clear communication of plans and expectations. When teaching virtually in spring 2020, fall 2020, and spring 2021, students benefited from regular communication about deadlines, resources, expectations, and the professor's availability to help. To experienced faculty, these communications may feel redundant, but students in our classes articulated that they were essential to their success in virtual learning. The same need for frequent, clear communication applies to in-person classes, especially when disruptions are inevitable and even temporary changes to course modalities are likely. It is also important to communicate your own constraints, to the degree that you are willing to do so. We are upfront with our students about our role as parents and the likelihood that even run-of-the-mill childhood colds that will automatically trigger school quarantines during this fourth pandemic semester. This openness may not always be met with grace and warmth from students or colleagues (this is especially dependent upon gender and race), but by modeling our own humanity we set an important example. We also call upon department heads and campus administrators to communicate clearly about policies, options for remote work and flexible course modalities, and available resources and support systems.

The fall 2021 semester is going to be challenging and we all long for the pre-pandemic days. But in our longing we cannot ignore the realities of the world in which we currently reside, a world that demands empathy, flexibility, grace, creativity, and communication.

\section{Pi Sigma Alpha Awardees}

Best Honors Thesis

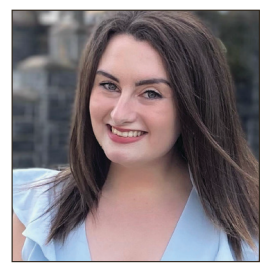

\section{Sela Dragich}

Georgetown

University, Delta Eta chapter

"The Impact of Institutions on

Access to Voting on US Reservations and Tribal Lands"

\section{Best Undergraduate Class Paper}

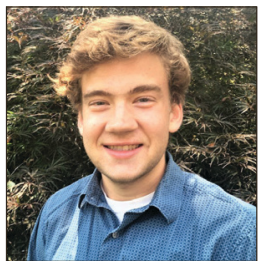

\section{Dillon Schweers}

University of Mary

Washington, Kappa Upsilon chapter

"Violence Against Journalists

in Mexico"

\section{Runners-up for Best Honors Thesis}

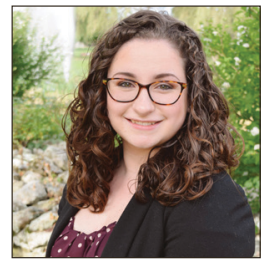

\section{Kaitlyn Fales}

Bryant University, Chi Nu chapter

"Instrumental vs. Expressive: A Study of Voter Behavioral Models Through the Lens of Identity in the 2016 Presidential Election"

\section{Runners-up for Best Undergraduate Class Paper}

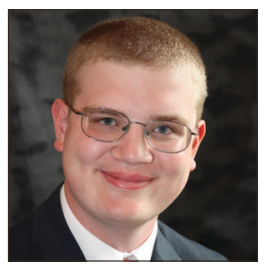

